General Hospital Building 149, 13th Street, Charlestown Navy Yard, Boston, Massachusetts 02129, USA. Phone: (617) 726-5619; Fax: (617) 724-9648; E-mail: pillai@helix.mgh.harvard.edu.

1. Mori, K., Ma, W., Gething, M.J., and Sambrook, J. 1993. A transmembrane protein with a cdc2+/ CDC28-related kinase activity is required for signaling from the ER to the nucleus. Cell. 74:743-756.

2. Cox, J.S., Shamu, C.E., and Walter, P. 1993. Transcriptional induction of genes encoding endoplasmic reticulum resident proteins requires a transmembrane protein kinase. Cell. 73:1197-1206.

3. Shamu, C.E., and Walter, P. 1996. Oligomerization and phosphorylation of the Ire $1 \mathrm{p}$ kinase during intracellular signaling from the endoplasmic reticulum to the nucleus. EMBO J. 15:3028-3039.

4. Sitia, R., and Braakman, I. 2003. Quality control in the endoplasmic reticulum protein factory. Nature. 426:891-894

5. Kaufman, R.J. 2002. Orchestrating the unfolded protein response in health and disease. J. Clin. Invest. 110:1389-1398. doi:10.1172/JCI200216886.
6. Imaizumi, K., et al. 2001. The unfolded protein response and Alzheimer's disease. Biochim. Biophys. Acta. 1536:85-96.

7. Ryu, E.J., et al. 2002. Endoplasmic reticulum stress and the unfolded protein response in cellular models of Parkinson's disease. J. Neurosci. 22:10690-10698.

8. Ozcan, U., et al. 2004. Endoplasmic reticulum stress links obesity, insulin action, and type 2 diabetes. Science. 306:457-461.

9. Aridor, M., and Balch, W.E. 1999. Integration of endoplasmic reticulum signaling in health and disease. Nat. Med. 5:745-751.

10. Lee, K., et al. 2002. IRE1-mediated unconventional mRNA splicing and S2P-mediated ATF6 cleavage merge to regulate XBP1 in signaling the unfolded protein response. Genes Dev. 16:452-466.

11. Shi, Y., et al. 1998. Identification and characterization of pancreatic eukaryotic initiation factor 2 alpha-subunit kinase, PEK, involved in translational control. Mol. Cell. Biol. 18:7499-7509.

12. Shen, X., et al. 2001. Complementary signaling pathways regulate the unfolded protein response and are required for C. elegans development. Cell. 107:893-903.

13. Reimold, A.M., et al. 2001. Plasma cell differentiation requires the transcription factor XBP-1.
Nature. 412:300-307.

14. Shaffer, A.L., et al. 2004. XBP1, downstream of Blimp-1, expands the secretory apparatus and other organelles, and increases protein synthesis in plasma cell differentiation. Immunity. 21:81-93.

15. Zhang, K., et al. 2005. The unfolded protein response sensor IRE $1 \alpha$ is required at 2 distinct steps in B cell lymphopoiesis. J. Clin. Invest. 115:268-281. doi:10.1172/JCI200521848.

16. Ho, S., Chaudhuri, S., Bacchawat, A.K., McDonald, K., and Pillai, S. 2000. Accelerated proteasomal degradation of membrane immunoglobulin heavy chains. J. Immunol. 164:4713-4719.

17. Kohler, G. 1980. Immunoglobulin chain loss in hybridoma lines. Proc. Natl. Acad. Sci. U. S. A. 77:2197-2199.

18. Haas, I.G., and Wabl, M. 1984. Immunoglobulin heavy chain toxicity in plasma cells is neutralized by fusion to pre-B cells. Proc. Natl. Acad. Sci. U. S. A. 81:7185-7188.

19. Urano, F., et al. 2000. Coupling of stress in the ER to activation of JNK protein kinases by transmembrane protein kinase IRE1. Science. 287:664-666.

20. Kosak, S.T., et al. 2002. Subnuclear compartmentalization of immunoglobulin loci during lymphocyte development. Science. 296:158-162.

\title{
Rab27a: a new face in $\beta$ cell metabolism-secretion coupling
}

Toru Aizawa ${ }^{1}$ and Mitsuhisa Komatsu²

${ }^{1}$ Center for Health, Safety, and Environmental Management and ${ }^{2}$ Graduate School of Medicine, Department of Aging Medicine and Geriatrics, Shinshu University, Matsumoto, Japan.

In pancreatic $\beta$ cells, not only insulin exocytosis per se, but translocation of $\beta$ granules toward the plasma membrane - an event upstream of exocytosis - are under the control of glucose. However, the molecular basis of this translocation has been poorly understood. Rab27a-mediated translocation of glucose-induced $\beta$ granules is reported in this issue of the JCI (see the related article beginning on page 388 ). Rab27a or its effector molecule may constitute a novel pharmacological target because potentiation of the Rab27a pathway is expected to restore $\beta$ cell glucose competency in patients with diabetes mellitus.

Insulin secretion by the pancreatic $\beta$ cell is tightly regulated by nutrients, especially by glucose. Selective impairment of glucose-stimulated insulin secretion (GSIS) is a salient feature of $\beta$ cell dysfunction in patients with type 2 diabetes mellitus. For

Nonstandard abbreviations used: $\left[\mathrm{Ca}^{2+}\right]_{i}$, intracellular $\mathrm{Ca}^{2+}$ concentration; GIP, glucose-dependent insulinotropic peptide; GLP1, glucagon-like peptide 1; GSIS, glucose-stimulated insulin secretion; $\mathrm{K}_{\mathrm{ATP}}$, ATP-sensitive $\mathrm{K}^{+}$; LC-CoA, long-chain CoA; RP, reserve pool; $\mathrm{RRP}$, readily releasable pool; $\mathrm{SU}$, sulfonylurea; TCA, tricarboxylic acid; t-SNARE, target membrane soluble $\mathrm{N}$-ethylmaleimide-sensitive factor attachment protein receptor; v-SNARE, vesicle membrane SNARE.

Conflict of interest: The authors have declared that no conflict of interest exists.

Citation for this article: J. Clin. Invest. 115:227-230 (2005). doi:10.1172/JCI200524269.
GSIS to occur, insulin-containing $\beta$ granules are transported to the vicinity of the plasma membrane, docked, and primed, so that they become readily releasable upon elevation of intracellular $\mathrm{Ca}^{2+}$ concentration $\left(\left[\mathrm{Ca}^{2+}\right]_{\mathrm{i}}\right)$ (Figure 1). The molecular basis for glucose stimulation of $\beta$ granule docking and/or replenishment of the readily releasable pool of granules is now at least in part clarified in this issue of the JCI (1).

\section{Mechanism of GSIS}

Glucose metabolism in the $\beta$ cell activates ATP-sensitive $\mathrm{K}^{+}\left(\mathrm{K}_{\text {ATP }}\right)$ channel-dependent and -independent signaling pathways (Figure 1). Mitochondrial metabolism is the key event in both pathways. Pyruvate, a product of glycolysis, enters the tricarboxylic acid
(TCA) cycle, and ATP is then generated. At the same time, cytosolic flux of the TCA cycle intermediate(s) (2) and/or activation of acetyl-CoA carboxylase (3) and activation of phospholipase C (4) take place. Anaplerosis (2), carboxylation of pyruvate to oxaloacetate and its entry to the TCA cycle - rather than entry of pyruvate into the TCA cycle via decarboxylation to acetyl-CoA - is critical for all of these outcomes (5).

The $\mathrm{K}_{\text {ATP }}$ channel-dependent events (Figure 1A) have been well characterized (6), and they include: (a) elevation of cytosolic ATP/ADP following ATP generation; (b) closure of the $\mathrm{K}_{\text {ATP }}$ channels; (c) membrane depolarization; (d) opening of L-type voltage-dependent $\mathrm{Ca}^{2+}$ channels; (e) $\mathrm{Ca}^{2+}$ influx; (f) elevation of $\left[\mathrm{Ca}^{2+}\right]_{i}$; and eventually $(\mathrm{g})$ triggering of exocytosis, i.e., fusion of $\beta$ granules in the readily releasable pool (RRP) and the plasma membrane. It should be noted that $\beta$ granules in the cell do not constitute a uniform population. A majority of them remain inside the cell and cannot immediately be releasable, thus forming a reserve pool (RP), whereas a small portion of them constitute the RRP, which is available for immediate secretion. 
A

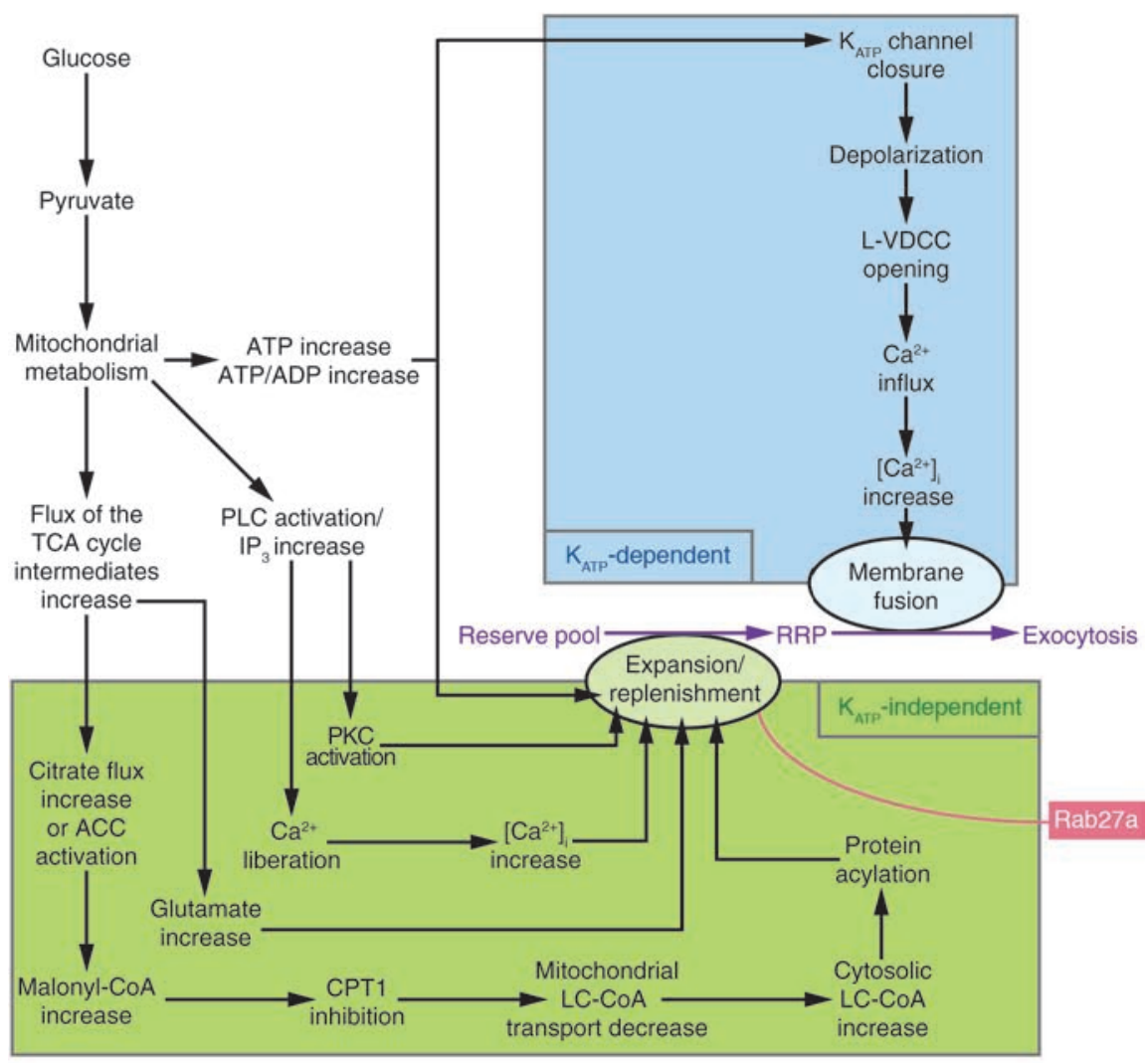

B

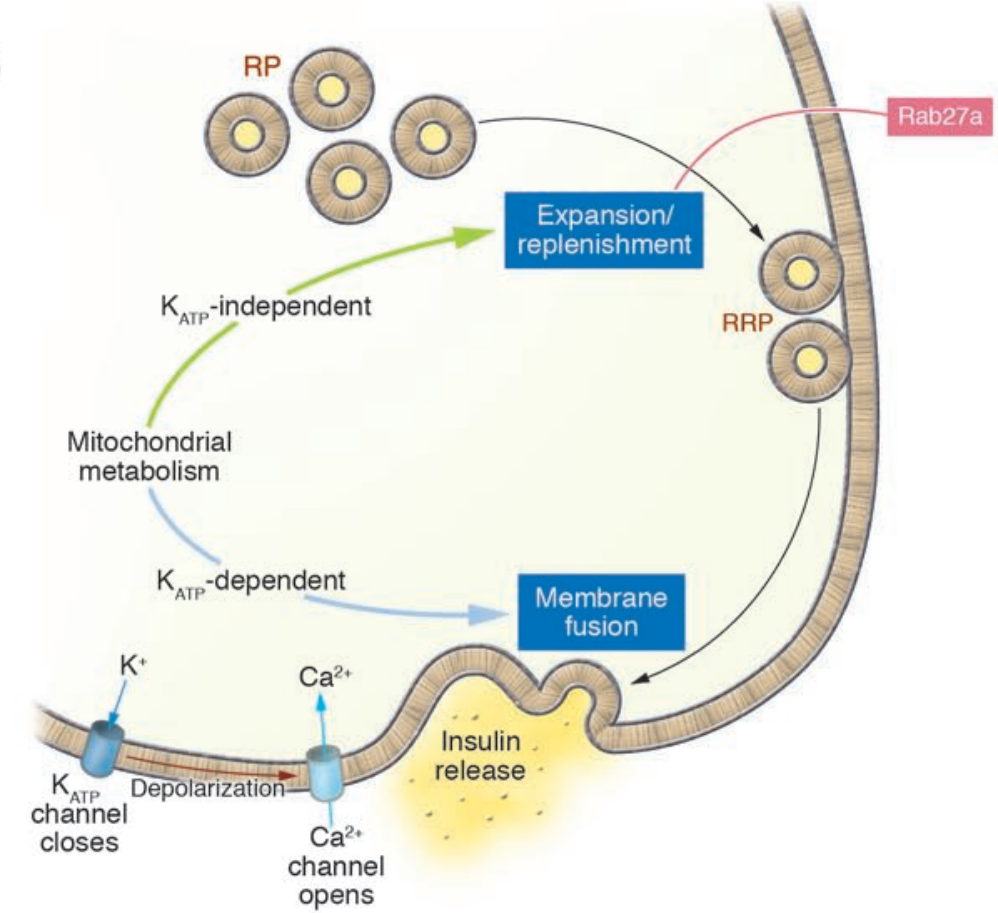

\section{Figure 1}

Metabolism-secretion coupling within the pancreatic $\beta$ cell. (A and $\mathbf{B}$ ) Elevation of ATP and ATP/ADP is the starting point for $\mathrm{K}_{\text {ATP }}$ channel-dependent signaling, which has been well elucidated, as shown here (6). Owing to $\left[\mathrm{Ca}^{2+}\right]_{i}$ elevation, fusion of $\beta$ granules in the RRP and the plasma membrane takes place, and this results in the first phase of glucoseinduced insulin secretion. The molecular basis for $\mathrm{K}_{\text {ATP }}$ channel-independent signaling (B) is not fully characterized. The end point of this signaling is expansion and/or replenishment of the RRP, after which a second phase occurs in which insulin release gradually increases. Upon glucose stimulation, $\mathrm{K}_{\text {ATP }}$ channel-dependent and -independent events take place. When an experimental protocol to detect time-dependent potentiation is employed $(16,17)$, expansion of the RRP can be quantified. Membrane fusion of the $\beta$ granules in the RRP is required and sufficient for first-phase insulin release, and, in addition, expansion and/or replenishment of the RRP is required for second phase release (see Figure 2). As shown in $\mathbf{A}$, as a result of anaplerosis (2), increased citrate flux (2) and/ or activation of acetyl-CoA carboxylase (ACC) (3) occurs, which results in expansion and/or replenishment of the RRP via the series of events indicated (10-12). Cytosolic flux of glutamate, by virtue of its uptake by $\beta$ granules, sensitizes the granules for fusion (15). Activation of phospholipase C (PLC), PKC, or an increase in inositol trisphosphate $\left(\mathrm{IP}_{3}\right)(4)$ and liberation of stored $\mathrm{Ca}^{2+}(13)$ also yield expansion and/or replenishment. ATP itself (14) and elevation of ATP/ADP (9) are also involved in this process. In this issue of the $\mathrm{JCl}$, Kasai et al. (1) report that Rab27a plays a critical role in replenishment of the RRP. CPT1, carnitine palmitoyl transferase 1; L-VDCC, L-type voltage-dependent $\mathrm{Ca}^{2+}$ channel.
Twelve years after its discovery, the $\mathrm{K}_{\mathrm{ATP}}$ channel-independent pathway is still not fully characterized (7-10). The so-called malonyl-CoA hypothesis (11) refers to a series of events, as follows: (a) increased citrate flux; (b) conversion of citrate to acetyl-CoA and then malonyl-CoA; (c) malonyl-CoA inhibition of carnitine palmitoyl transferase-1; (d) reduction of long-chain CoA (LC-CoA) incorporation into the mito- chondria; (e) LC-CoA accumulation in the cytosol; and (f) enhancement of exocytosis due to LC-CoA modification of signaling molecule(s) (Figure 1A). This is currently the most prominent hypothesis for the 
mechanism of the $\mathrm{K}_{\mathrm{ATP}}$ channel-independent glucose action. Palmitoylation is an example of reversible protein modification by LC-CoA, and we have demonstrated nutrient modulation of palmitoylated proteins in islet cells (12). Phospholipase $\mathrm{C}$ activation (4), liberation of $\mathrm{Ca}^{2+}$ from the intracellular store site (13), PKC activation $(4,13)$, and increase in the levels of ATP (14) and ATP/ADP (9) have also been proposed as mediators of this process. Cytosolic accumulation of glutamate and its uptake by $\beta$ granules, leading to an increased rate of exocytosis, has also been hypothesized (15) and has been the subject of much dispute.

\section{Biphasic response}

A square wave application of a high concentration of glucose produces biphasic insulin release (Figure 2), which contrasts with the monophasic release induced by sulfonylurea (SU) or a depolarizing concentration of $\mathrm{K}^{+}$. SU and a high concentration of $\mathrm{K}^{+}$fail to generate biphasic release despite the fact that the former closes the $\mathrm{K}_{\mathrm{ATP}}$ channel and the latter depolarizes the plasma membrane. In this regard, both agents activate $\mathrm{K}_{\mathrm{ATP}}$ channel-dependent signaling. Thus, glucose-induced first-phase insulin release is considered to be due to the fact that the $\mathrm{K}_{\mathrm{ATP}}$ channeldependent elevation of $\left[\mathrm{Ca}^{2+}\right]_{i}$ promotes fusion of the $\beta$ granules already in the RRP. The second phase, characterized by a gradual increase of insulin release following the initial peak, is considered to be due to the $\mathrm{K}_{\text {ATP }}$ channel-independent expansion and/ or replenishment of the RRP from the RP. Upon elevation of extracellular glucose, $\mathrm{Ca}^{2+}$-induced fusion of granules already in the RRP occurs within minutes, and expansion and/or replenishment of the RRP from the RP is in progress several minutes later.

GSIS occurring under full activation of the $\mathrm{K}_{\mathrm{ATP}}$ channel with diazoxide and depolarization with a high concentration of $\mathrm{K}^{+}$is a measure of $\mathrm{K}_{\mathrm{ATP}}$ channel-independent glucose action (7-10). The expansion and/or replenishment of the RRP can be quantified if a sequential stimulation protocol is employed $(16,17)$ : initial stimulation with a high concentration of glucose followed by the triggering (by fusion of $\beta$ granule and the plasma membrane induced by $\left[\mathrm{Ca}^{2+}\right]_{i}$ elevation; see above) by a depolarizing concentration of $\mathrm{K}^{+}$in the presence of a nonstimulatory concentration of glucose. Here, glucose pretreatment yields increased insulin release during stim- ulation with a high concentration of $\mathrm{K}^{+}$. This phenomenon has long been known as time-dependent potentiation by glucose, which is fully operative under stringently $\mathrm{Ca}^{2+}$-free conditions and/or activation of the $\mathrm{K}_{\text {ATP }}$ channel $(16,17)$.

Expansion and/or replenishment of the RRP is a consequence of increased $\beta$ granule movement (13) and margination of it toward the cell periphery $(18,19)$, both of which are due to chemical modification of the granule $(13,18-20)$. The insulin secretion rate, which reflects the fusion rate of $\beta$ granules and the plasma membrane, is thus increased without upregulation of the triggering signal, $\left[\mathrm{Ca}^{2+}\right]_{\mathrm{i}}$.

\section{Rab27a as a specific mediator of GSIS}

A small, monomeric GTP-binding protein, Rab, plays a critical role in formation, trafficking, and tethering of vesicles to the target compartment in endocrine and nonendocrine cells, and a functional role of Rab in insulin secretion has been previously demonstrated (21). Also, Cdc42, a Rho family small GTPase, has been proposed as a specific mediator of GSIS (22). Nevertheless, the process of insulin secretion cannot simply be viewed as the fusion of $\beta$ granules and the plasma membrane, and the classic 2-compartment model described above best accommodates the dynamism of insulin secretion under various physiological and experimental conditions. In this model, the connection between small GTP-binding proteins and the $\mathrm{K}_{\mathrm{ATP}}$ channel-dependent and-independent pathways is currently unclear. For example, the small GTP proteins may be involved in the pairing of the target membrane soluble $N$-ethylmaleimide-sensitive factor attachment protein receptor (t-SNARE) with the vesicle membrane SNARE (v-SNARE) and thus play a role in $\mathrm{Ca}^{2+}$-induced triggering downstream of the $\mathrm{K}_{\mathrm{ATP}}$ channel closure. Alternatively, these proteins may be needed for initiation and maintenance of $\beta$ granule transit from the RP to the RRP. If this is the case, the GTP proteins are mediators of expansion and/or replenishment of RRP, and therefore they are effector molecules in the $\mathrm{K}_{\text {ATP }}$ channelindependent pathway. The possibility may even exist that the GTP proteins are engaged in both of the glucose-induced signaling pathways. At any rate, in order to delineate the role of Rab in glucose signaling, Kasai et al. endeavored to quantify the triggering and replenishment of the RRP using intact and Rab-defective $\beta$ cells (1).
In this issue, Kasai et al. (1) examine the $\beta$ cells of ashen mice, which have a mutated, nonfunctioning form of Rab27a. These animals exhibited glucose intolerance with insufficient insulin secretion in vivo, and in the isolated islets, GSIS was impeded; the number of docked $\beta$ granules was reduced, and glucose-induced replenishment of these granules was clearly subnormal. Interaction of granuphilin with syntaxin 1a was diminished in ashen islets. Because granuphilin is an effector of Rab, and syntaxin 1a and SNAP-25 associate with VAMP2 (a v-SNARE), diminished granuphilin-syntaxin 1a interaction in ashen islets suggested impaired SNARE complex formation as an underlying mechanism of abnormal granule trafficking.

Quite interestingly, $\mathrm{K}_{\mathrm{ATP}}$ channel-dependent glucose action, for which elevation of $\left[\mathrm{Ca}^{2+}\right]_{\mathrm{i}}$ induced by glucose was employed as an index, was normal in ashen $\beta$ cells (1). In addition, $\mathrm{K}_{\mathrm{ATP}}$ channel-independent glucose action, insulin secretion in response to a high concentration of glucose in the presence of diazoxide and a high concentration of $\mathrm{K}^{+}$, was intact. Yet both phases of GSIS were impeded. On the other hand, insu-

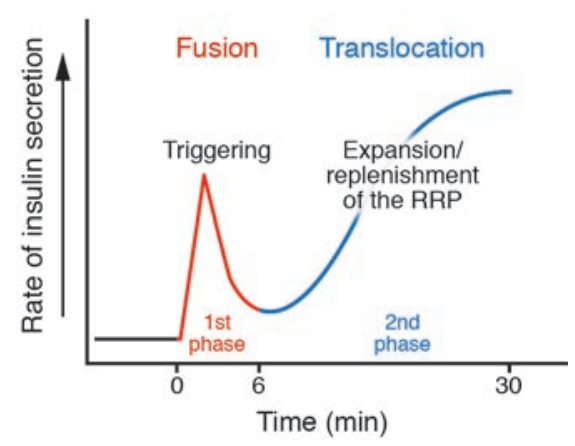

Figure 2

A schematic presentation of glucose-induced biphasic insulin secretion by islet $\beta$ cells. Stimulation by a high concentration of glucose elicits a rapid increase in insulin secretion within 1-2 minutes (first phase). Within 10 minutes, in the presence of the same stimulatory concentration of glucose, the secretion rate is decreased, and it gradually begins to increase again thereafter (second phase). Second-phase insulin release is more prominent in rat and human than in mouse $\beta$ cells. First-phase insulin release is generated by fusion of $\beta$ granules already in the RRP and the plasma membrane, which is called triggering. For the second phase, granules translocate from the RP to the RRP, which yields expansion and/or replenishment of the RRP. The first and second phases of insulin secretion are due to $\mathrm{K}_{\text {ATP }}$ channel-dependent and -independent glucose signaling, respectively, as outlined in Figure 1. 
lin secretion induced by pharmacological agents including depolarizing concentrations of $\mathrm{K}^{+}$, forskolin (an adenylyl cyclase activator), and phorbol ester (an agonist of PKC) was normal: the secretory defect was thus specific to glucose. Where and how is exocytosis impaired by the absence of functional Rab27a?

\section{Does Rab27a keep $\beta$ cell glucose competency downstream of incretin and/or cAMP?}

Glucagon-like peptide 1 (GLP1) and glucose-dependent insulinotropic peptide (GIP) are gut hormones that stimulate cAMP generation in the $\beta$ cell and thereby potentiate GSIS. Such peptides are collectively called incretins. cAMP is a positive regulator of exocytosis at multiple steps, including the expansion of the RRP in synergy with the $\mathrm{K}_{\mathrm{ATP}}$ channel-independent glucose signaling (16). Mice with targeted disruption of the genes encoding receptors for both GLP1 and GIP were created recently (23) and are remarkably reminiscent of ashen mice. Namely, the knockout mice showed normal ambient plasma glucose concentrations, impaired glucose tolerance with insufficient insulin secretion in vivo, and reduction of both phases of GSIS in the isolated islets. Thus, the following scenario is plausible: Rab27a is involved in replenishment of the RRP downstream of cAMP, and absence of this signaling from birth may cause constitutive defects in the expansion and/or replenishment of the RRP, yielding reduction in the number of docked $\beta$ granules. In fact, cAMP/Rab27a signaling plays a critical role in the accumulation of melanosomes in the actin-rich region (24). Melanosomes are lysosome-related organelles containing melanin pigment, and at the cell periphery, they interact with actin via a Rab27a-containing complex. This mechanism is essential for determining melanosome localization.

Normal enhancement of GSIS by forskolin and phorbol ester in ashen $\beta$ cells was not unexpected (1). These pharmacological agents produce supraphysiological elevation of cAMP and activation of PKC, respectively, which potently augment insulin exocytosis through stimulatory effects not only at the step of RRP replenishment but also at the voltage-dependent $\mathrm{Ca}^{2+}$ channel or $\mathrm{Ca}^{2+}$-induced fusion of $\beta$ granules and the plasma membrane. Therefore, $\beta$ granule dysregulation associated with a defect in Rab27a function may well be overridden. Although the glucose-induced rise in $\left[\mathrm{Ca}^{2+}\right]_{i}$ at room temperature was normal in ashen islets (1), this does not exclude the possibility of minor metabolic suppression at $37^{\circ} \mathrm{C}$. Minute impairment of glucose metabolism leads to selective inhibition of the $\mathrm{K}_{\mathrm{ATP}}$ channel-dependent insulinotropic action of glucose, leaving the $\mathrm{K}_{\mathrm{ATP}}$ channel-independent pathway intact (9).

This work from Izumi's laboratory elegantly discloses a previously unrecognized facet of metabolism-secretion coupling in the $\beta$ cell. Currently, compounds that act to close the $\mathrm{K}_{\mathrm{ATP}}$ channel are the only available insulinotropic agents, and they simply cause fusion of the $\beta$ granules in the RRP and the plasma membrane. A pharmacological agent that acts on the Rab27a pathway may become the long-awaited tool to potentiate glucose-induced insulin secretion and therefore present a new therapeutic option for the treatment of $\beta$ cell dysfunction in diabetes.

Address correspondence to: Toru Aizawa, Center for Health, Safety, and Environmental Management, Shinshu University, 3-1-1, Asahi, Matsumoto, Japan. Phone: 81263-37-2157; Fax: 81-263-37-2183; E-mail: taizawa@gipac.shinshu-u.ac.jp.

1. Kasai, K., et al. 2005. Rab27a mediates the tight docking of insulin granules onto the plasma membrane during glucose stimulation. J. Clin. Invest. 115:388-396. doi:10.1172/JCI200522955.

2. Farfari, S., Schulz, V., Corkey, B., and Prentki, M. 2000. Glucose-regulated anaplerosis and cataplerosis in pancreatic beta-cells: possible implication of a pyruvate/citrate shuttle in insulin secretion. Diabetes. 49:718-726.

3. da Silva Xavier, G., et al. 2003. Role for AMP-activated protein kinase in glucose-stimulated insulin secretion and preproinsulin gene expression. Biochem. J. 371:761-774.

4. Zawalich, W.S., and Zawalich, K.C. 1996. Regulation of insulin secretion by phospholipase C. Am.J. Physiol. 271:E409-E416.

5. Nicholls, L.I., Ainscow, E.K., and Rutter, G.A. 2002. Glucose-stimulated insulin secretion does not require activation of pyruvate dehydrogenase: impact of adenovirus-mediated overexpression of $\mathrm{PDH}$ kinase and PDH phosphate phosphatase in pancreatic islets. Biochem. Biophys. Res. Commun. 291:1081-1088.

6. Seino, S., and Miki, T. 2003. Physiological and pathophysiological roles of ATP-sensitive $\mathrm{K}^{+}$chan- nels. Prog. Biophys. Mol. Biol. 81:133-176.

7. Sato, Y., et al. 1992. Dual functional role of membrane depolarization/ $\mathrm{Ca}^{2+}$ influx in rat pancreatic B-cell. Diabetes. 41:438-443.

8. Gembal, M., Gilon, P., and Henquin, J.C. 1992. Evidence that glucose can control insulin release independently from its action on ATP-sensitive $\mathrm{K}^{+}$channels in mouse B cells. J. Clin. Invest. 89:1288-1295.

9. Henquin, J.C. 2000. Triggering and amplifying pathways of regulation of insulin secretion by glucose. Diabetes. 49:1751-1760.

10. Aizawa, T., Sato, Y., and Komatsu, M. 2002. Importance of non-ionic signals for glucoseinduced biphasic insulin secretion. Diabetes. 51(Suppl. 1):S96-S98.

11. Corkey, B.E., Deeney, J.T., Yaney, G.C., Tornheim, K., and Prentki, M. 2000. The role of long-chain fatty acyl-CoA esters $\beta$-cell signal transduction. J. Nutr. 130(2S Suppl.):299S-304S.

12. Yamada, S., et al. 2003. Nutrient modulation of palmitoylated 24-kilodalton protein in rat pancreatic islets. Endocrinology. 144:5232-5241.

13. Niki, I., et al. 2003. $\mathrm{Ca}^{2+}$ influx does not trigger glucose-induced traffic of the insulin granules and alteration of their distribution. Exp. Biol. Med. 228:1218-1226.

14. Takahashi, N., et al. 1999. Post-priming actions of ATP on $\mathrm{Ca}^{2+}$-dependent exocytosis in pancreatic $\beta$ cells. Proc. Natl. Acad. Sci. U. S. A. 96:760-765.

15. Maechler, P., and Wollheim, C.B. 1999. Mitochondrial glutamate acts as a messenger in glucose-induced insulin exocytosis. Nature. 402:685-689.

16. Yajima, H., et al. 1999. Cyclic AMP enhances insulin secretion by an action on the ATP-sensitive $\mathrm{K}^{+}$ channel-independent pathway of glucose signaling in rat pancreatic islets. Diabetes. 48:1006-1012.

17. Komatsu, M., et al. 1999. Augmentation of $\mathrm{Ca}^{2+}$ stimulated insulin release by glucose and long chain fatty acids in rat pancreatic islets: free fatty acids mimic ATP-sensitive $\mathrm{K}^{+}$channel-independent insulinotropic action of glucose. Diabetes. 48:1543-1549.

18. Olofsson, C.S., Salehi, A., Holm, C., and Rorsman, P. 2004. Palmitate increases L-type $\mathrm{Ca}^{2+}$ currents and the size of the readily releasable granule pool in mouse pancreatic $\beta$-cells. J. Physiol. 557:935-948.

19. Thurmond, D.C., Gonelle-Gispert, C., Furukawa, M., Halban, P.A., and Pessin, J.E. 2003. Glucosestimulated insulin secretion is coupled to the interaction of actin with the t-SNARE (target membrane soluble $\mathrm{N}$-ethylmaleimide-sensitive factor attachment protein receptor protein) complex. Mol. Endocrinol. 17:732-742.

20. Daniel, S., Noda, M., Straub, S.G., and Sharp, G.W. 1999. Identification of the docked granule pool responsible for the first phase of glucose-stimulated insulin secretion. Diabetes. 48:1686-1690.

21. Yaekura, K., et al. 2003. Insulin secretory deficiency and glucose intolerance in Rab3A null mice. J. Biol. Chem. 278:9715-9721.

22. Nevins, A.K., and Thurmond, D.C. 2004. A direct interaction between Cdc42 and VAMP2 regulates SNARE-dependent insulin exocytosis. J. Biol. Chem. doi:10.1074/jbc.M409528200.

23. Preitner, F., et al. 2004. Gluco-incretins control insulin secretion at multiple levels as revealed in mice lacking GLP-1 and GIP receptors. J. Clin. Invest. 113:635-645. doi:10.1172/JCI200420518.

24. Passeron, T., et al. 2004. Cyclic AMP promotes a peripheral distribution of melanosomes and stimulates melanophilin/Slac2-a and actin association. FASEB J. 18:989-991. 